\title{
Interactive comment on "Global deposition of speciated atmospheric mercury to terrestrial surfaces: an overview" by Lei Zhang et al.
}

\section{Lei Zhang et al.}

Izhang12@nju.edu.cn

Received and published: 19 August 2019

The revised manuscript is attached for the editor and reviewers.

Please also note the supplement to this comment:

https://www.atmos-chem-phys-discuss.net/acp-2019-347/acp-2019-347-AC1-

supplement.pdf

Interactive comment on Atmos. Chem. Phys. Discuss., https://doi.org/10.5194/acp-2019-347, 2019. 